\title{
Uji GPS Tracking Dalam Skala Transportasi Antar Kota
}

\author{
Iftitahatul Hanifah*1, Bambang Nurcahyo Prastowo ${ }^{2}$ \\ ${ }^{1}$ Prodi Elektronika dan Instrumentasi Jurusan Ilmu Komputer dan Elektronika, FMIPA UGM \\ ${ }^{2}$ Jurusan Ilmu Komputer dan Elektronika, FMIPA UGM \\ e-mail: *1iftihaanifah@gmail.com, ${ }^{2}$ prastowo@mail.ugm.ac.id
}

\begin{abstract}
Abstrak
Akurasi dari suatu sistem penting dilakukan agar data yang didapatkan sesuai. Tiaptiap alat memiliki tingkat akurasi yang berbeda, begitu pula untuk tingkat akurasi dari sistem pelacakan. Sistem pelacakan digunakan untuk melihat posisi suatu kendaraan. Sistem pelackaan biasanya menggunakan alat GPS untuk mendapatkan data posisi berupa titik koordinat.

Di dalam penelitian ini dibangun sebuah sistem uji GPS Tracking untuk melihat data posisi kendaraan. Digunakan dua GPS, yaitu GPS tipe cn06 sebagai GPS yang akan dilihat keakurasian datanya dan GPSmap 76CSx sebagai data sekunder yang digunakan sebagai acuan. Data-data yang diperoleh akan diseleksi dan dianalisis untuk melihat faktor apa saja yang mempengaruhi keakurasiannya. Data yang diseleksi berupa titik koordinat (latitude dan longitude), waktu, dan kecepatan. Seleksi data menggunakan regular expression didalam bahasa pemrograman PHP. Data-data kemudian akan ditampilkan dalam bentuk marker pada web menggunakan Google Maps API. Analisis data posisi dilakukan dengan membandingkan dua marker yang memiliki waktu pengambilan data yang berdekatan.

Hasil pengujian menunjukan faktor yang menyebabkan keakurasian data posisi GPS adalah konstan tidaknya kecepatan kendaraan. Faktor lain yang menghambat seperti gedung bertingkat, pohon besar tidak akan berpengaruh apabila kecepatan motor dijaga tetap konstan. Pada pengujian antarkota juga didapatkan hasil yang sama, yaitu faktor penting dalam keakurasian posisi adalah kecepatan.
\end{abstract}

Kata kunci-GPS tracking, latitude, longitude, tingkat akurasi, regular expression, PHP, marker

Abstract

The accuracy level of a system in order to obtain an accurate data. Each tool has a different level of accuracy as well as to the accuracy of tracking system. This tracking system is used to locate a vehicle. It is usually using GPS tool to obtain position data in coordinate point.

A GPS tracking testing system is constructed in this research to see positional data obtained from the GPS. Two GPS were used, a cn06 GPS as test GPS and GPSmap 76CSx as secondary data. Obtained data will be selected in coordinates, time, and speed. Selection of data is using regular expression in PHP. These data will later be displayed in the form of maker and web using Google Maps. The analysis will be done by comparing two markers that have adjacent time of retrieval.

The result of this research shows that the factor that affect the difference in the accuracy of GPS is the speed of the vehicle. Other obstructing factors such as multi-storey building and large trees will have no effect if the speed is keep at constant pace. In this intercity testing, the result is similiar to previous study, that the important factor is the speed.

Kata kunci-GPS tracking, latitude, longitude, level of accuracy, regular expression, PHP, marker

Received October $13^{\text {th }}, 2016$; Revised October $20^{\text {th }}, 2016$; Accepted October $27^{\text {th }}, 2016$ 


\section{PENDAHULUAN}

$\mathrm{M}$ odul GPS yang ada dipasaran beragam harganya, dari yang murah hingga yang mahal. Mahal tidaknya suatu GPS akan mempengaruhi keakurasian dari data posisi yang diperoleh. Akurasi adalah seberapa dekat nilai hasil pengukuran dengan nilai sebenarnya (true value) atau nilai yang dianggap benar (accepted value) [1]. Penting untuk melihat keakurasian data posisi dari suatu GPS dikarenakan GPS seringkali digunakan untuk sistem pelacakan. Sistem pelacakan yaitu untuk mengetahui posisi dari suatu kendaraan. Oleh karena itu perlu dilihat keakurasian dari data posisi yang diperoleh agar ketika sistem digunakan, diperoleh data yang benar-benar akurat.

Sistem pelacakan ini umumnya menggunakan GPS (Global Posistioning System) untuk menentukan posisi kendaraan [2]. Sistem ini biasanya menggunakan komponen komunikasi seperti jaringan selular atau satelit untuk mengirimkan posisi kendaraan kepada pengguna di tempat lain. Perangkat ini berukuran kecil sehingga dapat diletakkan dimana saja dan dapat dengan mudah diintegrasikan dengan perangkat lain. Pengguna juga dapat menjalankan sendiri tanpa memerlukan bantuan dari pihak luar. Sehingga pemantauan atau pelacakan posisi kendaraan dapat dilakukan dengan mudah.

\section{METODE PENELITIAN}

\subsection{Diskripsi Sistem}

Sistem yang dibuat merupakan sistem untuk melihat keakurasian data hasi uji GPS tracking yang dilakukan. Berikut adalah blok diagram rancangan pembuatan system yang ditunjukkan pada Gambar 1.

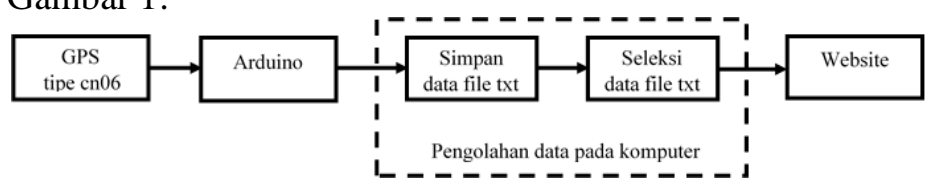

Gambar 1 Blok diagram rancangan sistem

Proses tracking GPS membutuhkan beberapa tahapan. Secara umum, proses tracking GPS meliputi deteksi posisi, pengolahan data posisi dan analisis hasil data posisi. GPS receiver dari GPS tipe cn06 akan mendeteksi posisi kendaraan yang sedang berjalan dengan menangkap sinyal dari satelit GPS [3]. GPS tipe cn06 dihubungkan dengan Arduino untuk memproses datadata hasil pembacaan GPS. Pengolahan data selanjutnya akan dilakukan pada komputer, yaitu menyimpan data-data yang diperoleh kedalam file txt lalu menyeleksi data-data tersebut. Penyimpanan data menjadi file txt menggunakan perangkat lunak tambahan yang telah disediakan. Sedangkan penyeleksian data-data yang dibutuhkan menggunakan regular expression dalam bahasa pemrogram PHP. Seleksi data dilakukan dengan mendeteksi pola tertentu yang ada pada file txt. Setelah ditemukan pola yang sesuai, data-data yang dibutuhkan akan dikelompokkan lalu ditampilkan [4]. Data yang sudah diseleksi akan ditampilkan pada website dalam bentuk Google Maps yang dijalankan menggunakan internet. Data yang ditampilkan pada Google Maps berbentuk marker (titik koordinat latitude dan longitude) dan informasi berupa waktu pengambilan data serta kecepatan dari kendaraan. Data hasil pengujian akan dianalisis sehingga didapatkan hipotesa-hipotesa tertentu, akan dilakukan konfirmasi ulang terkait hipotesa yang didapat. Konfirmasi dilakukan dengan pengujian sesuai paramaterparameter yang telah ditentukan sehingga diperoleh kesimpulan yang sesuai dan akurat. Diagram alir algoritma pembacaan GPS ditunjukkan pada Gambar 2. 


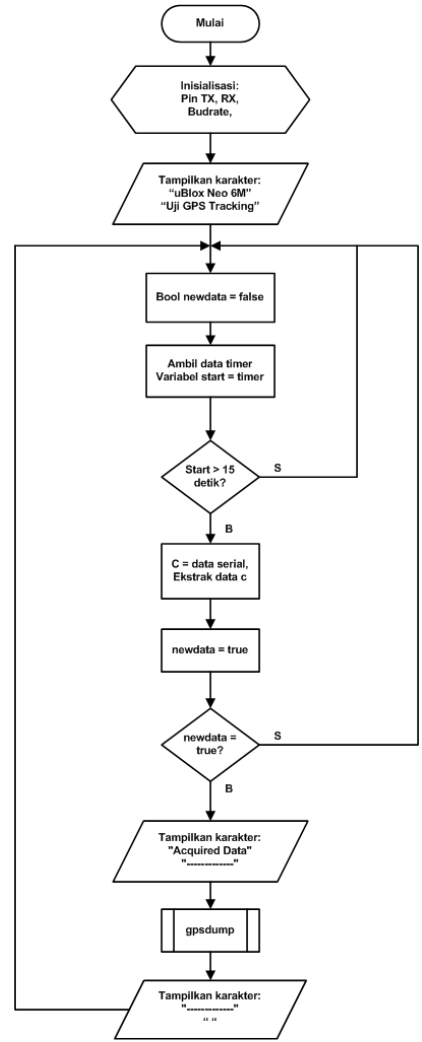

Gambar 2 Diagram alir algortima pembacaan GPS

\subsection{Perancangan Pembuatan Map untuk Analisi Data}

Google Maps akan digunakan sebagai tempat untuk menampilkan hasil uji GPS tracking dalam bentuk marker. Marker yang ditampilkan berupa representasi dari titik koordinat (latitude dan longitude) yang didapatkan dari data pembacaan GPS. Berikut ini merupakan diagram alir rancangan web yang digunakan sebagai tempat menampilkan hasil berupa marker sesuai dengan Gambar 3.

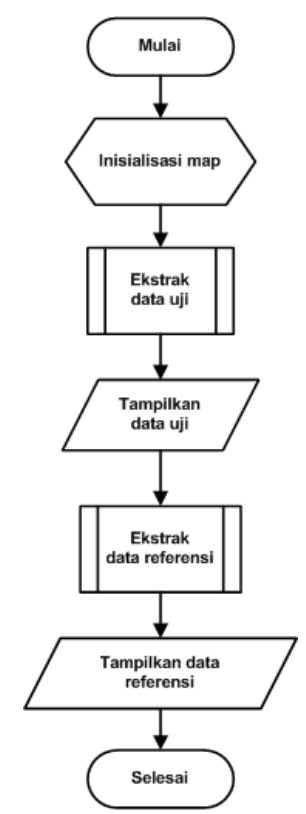

Gambar 3 Diagram alir rancangan website 
Gambar 3 menunjukkan diagram alir dari perancangan website. Sistem dimulai dengan menginsialisasi map. Inisialisasi ini digunakan agar website yang dibuat dapat menampilkan Google Maps. Menampilkan Google Maps dilakukan dengan pencarian citra satelit sehingga harus dilakukan secara online. Proses selanjutnya adalah Ekstrak data uji dan ekstrak data referensi. Masing-masing data hasil ekstraksi akan ditampilkan dalam bentuk marker. Pada diagram alir perancangan yang ditunjukkan Gambar 4 terdapat proses ekstrak data uji. Ekstrak data uji digunakan untuk menyeleksi dan mengelompokkan data-data yang akan ditampilkan. Diagram alir ekstraksi data uji ditunjukkan pada Gambar 4.

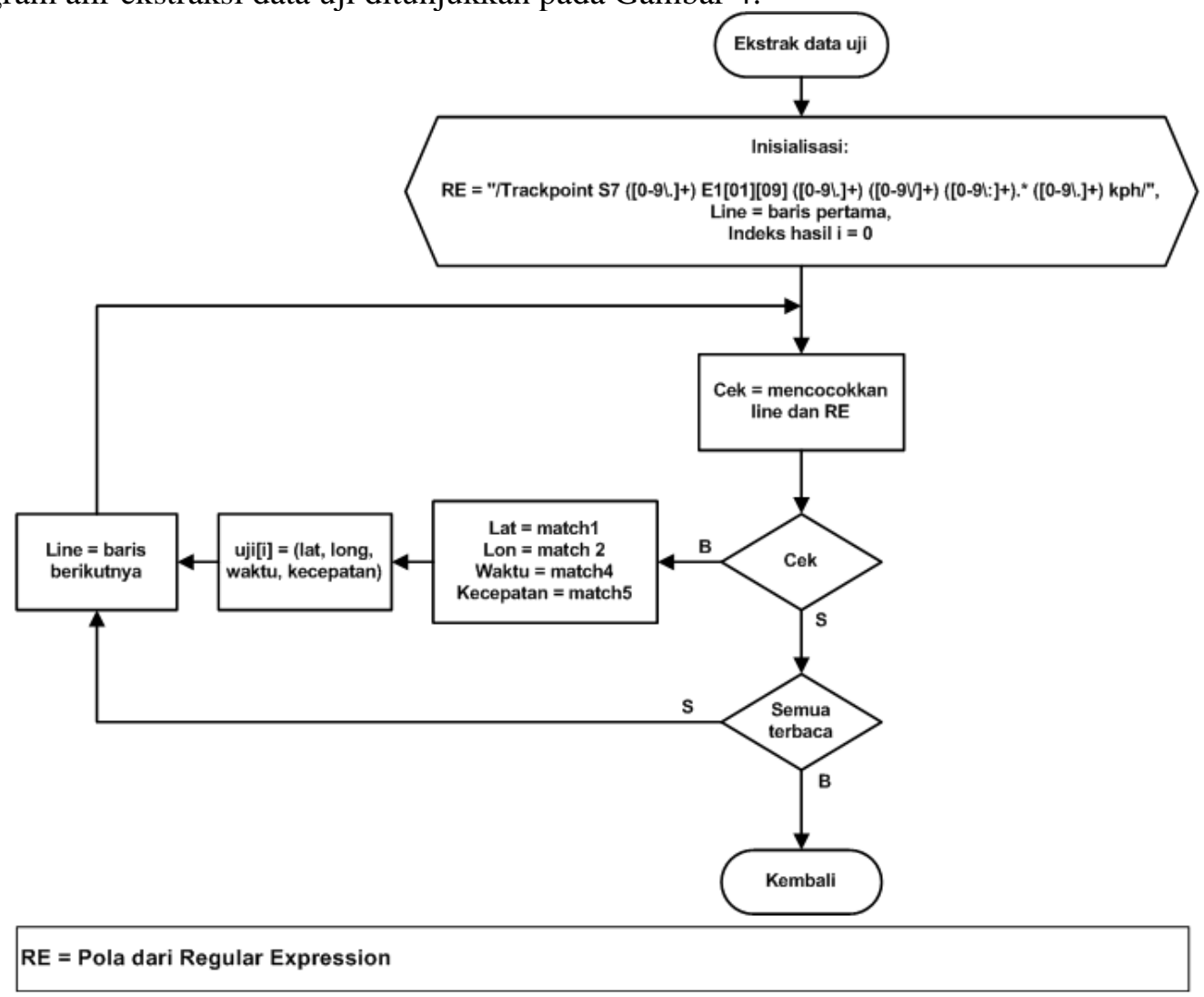

Gambar 4 Diagram alir ekstrak data uji

Sistem dimulai dengan menginsialisasi map. Inisialisasi ini digunakan agar website yang dibuat dapat menampilkan Google Maps. Pada diagram diatas menunjukkan proses ekstrak data uji. Proses dimulai dengan menginisialisasi RE sebagi pola penyeleksian dan pengelompokan data. Terdapat line yang merupakan baris pertama dari file, dan indeks hasil i bernilai 0 . Pada sistem ini akan dilakukan pengecekan yaitu mencocokan antara line dengan RE. Jika setelah dicocokkan terdapat kesesuaian pola, latitude akan mengambil data kelompok 1, longitude data kelompok 2, waktu berupa data kelompak 4, dan kecepatan mengambil data kelompok 5. Proses selanjutnya adalah indeks data hasil uji i akan berisi data-data yang telah dikelompokkan. Kemudian dilakukan pengecekan pada baris berikutnya. Proses akan berlangsung selama terdapat kecocokan antara line dengan pola RE. Namun jika tidak ada kecocokan, maka akan dilihat apakah baris yang ada sudah terbaca semua atau belum. Jika baris sudah terbaca semua maka proses selesai, jika tidak maka proses akan dilanjutkan dengan membaca baris selanjutnya lalu dilakukan pengecekan kembali untuk pola RE.

Proses selanjutnya yaitu ekstrak data referensi. Pada dasarnya ekstrak data referensi sama dengan ekstrak data uji, yang membedakan adalah ekstrak data referensi memiliki tiga pola RE untuk mendapatkan data yang akan ditampilkan. Berikut diagram alir ekstraksi data referensi yang ditunjukkan pada Gambar 5.

IJEIS Vol. 6, No. 2, October 2016 : $175-186$ 


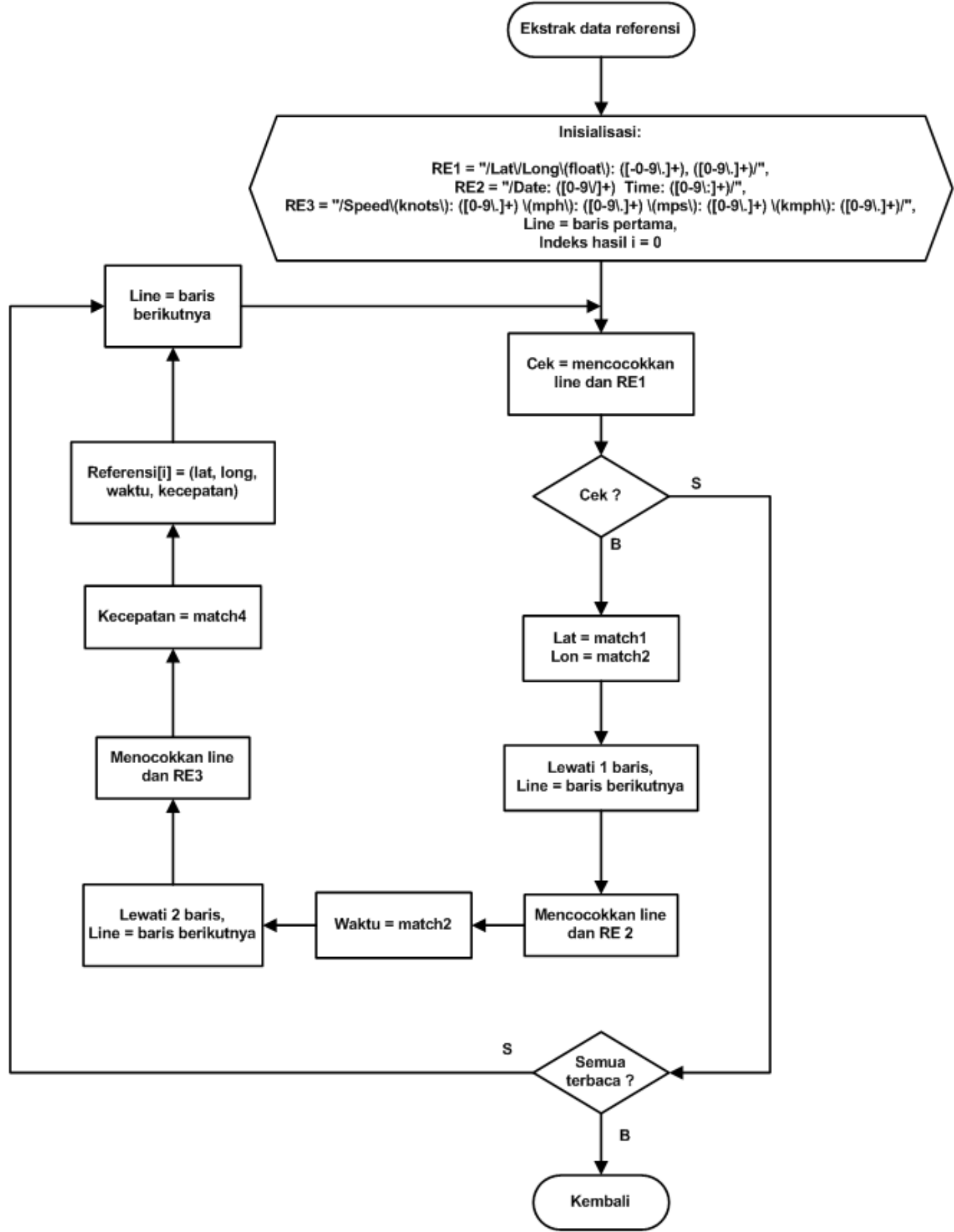

Gambar 5 Diagram alir ekstrak data referensi

\subsection{Perancangan Perangkat Keras}

Perangkat keras yang digunakan dalam penelitian ini yaitu board Arduino, GPS tipe cn06 dan GPSmap 76CSx. Board Arduino berfungsi untuk memproses data. Rancangan perangkat keras dari sistem ditunjukkan pada Gambar 6. 


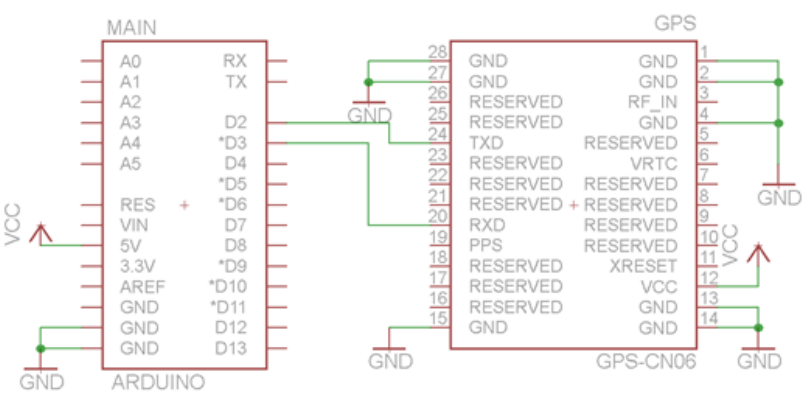

Gambar 6 Rangkaian perangkat keras

Perangkat keras yang digunakan yaitu board Arduino, GPS tipe cn06 dan GPSmap 76CSx. Board Arduino berfungsi untuk memproses data. Data-data yang diproses meliputi semua data yang diperoleh dari hasil pembacaan GPS, baik berupa koordinat posisi (latitude dan longitude), tanggal, waktu, kecepatan dan ketinggian. GPS tipe cn06 digunakan sebagai GPS receiver posisi kendaraan. GPS receiver ini terhubung dengan Arduino dan akan mengirimkan datanya pada Arduino sehingga data tersebut dapat diproses. GPSmap 76CSx juga digunakan sebagai GPS receiver. Akan tetapi datanya dijadikan sebagai data sekunder. Data sekunder ini digunakan sebagai pembanding hasil data GPS tipe cn06 sehingga dapat terlihat hal-hal yang akan mempengaruhi keakurasiannya.

Pin TX pada GPS tipe cn06 dihubungkan dengan pin D2 pada Arduino, sedangkan pin RX pada GPS tipe cn06 dihubungkan dengan pin D3 pada Arduino. Selanjutnya dari Arduino akan dihubungkan ke komputer secara serial. Untuk GPSmap 76CSx akan langsung dihubungkan dengan komputer. Hal ini dikarenakan GPSmap 76CSx merupakan GPS yang sudah terkalibrasi dan memiliki fitur untuk menyimpan data-data yang diperoleh pada devicenya sehingga tidak memerlukan peralatan tambahan untuk memproses datanya. Untuk mendapatkan data yang ada pada device GPSmap 76CSx dapat dilakukan dengan komunikasi serial langsung menggunakan kabel USB.

\subsection{Perancangan Perangkat Lunak}

Perangkat lunak yang digunakan untuk perancangan sistem :

1. Google Maps digunakan untuk menampilkan peta atau citra satelit pada halaman yang dirancang sebagai tempat untuk mengolah data.

2. Bahasa pemrograman web, HTML, Javascript, dan PHP. PHP digunakan untuk menyeleksi data-data yang didapat dari hasil tracking yang sudah dsimpan dalam file txt. Seleksi data ini menggunakan regular expression dalam bahasa pemrograman PHP. Data yang diseleksi akan ditampilkan pada Google Maps dalam bentuk marker.

3. Perangkat lunak tambahan yaitu CoolTerm dan MapSource, masing-masing digunakan untuk menyimpan data-data yang didapatkan menjadi file txt.

\subsection{Perancangan Antarmuka Sistem}

Antarmuka sistem digunakan untuk memudahkan dalam melihat hasil data uji GPS tracking. Antarmuka ini berisi list dari link-link yang merupakan hasil dari pengujian. Dimulai dari pengujian awal, pengujian konfirmasi, dan pengujian antarkota. Antarmuka dibangun dengan sistem pemorgraman web menggunakan bahasa pemrograman HTML [5]. Dengan antarmuka ini hanya perlu membuka link-link yang ada tanpa perlu mengetikkan alamat untuk membuka file yang dibuat pada website. Akan tetapi antarmuka ini tidak real time, artinya linklink yang ditampilkan pada antarmuka tidak ter-update secara otomatis. Link hasil tracking terbaru dapat ditambahkan dengan memprogram ulang antarmuka yang dibuat. Rancangan tampilan antarmuka sistem ditunjukkan pada Gambar 7. 


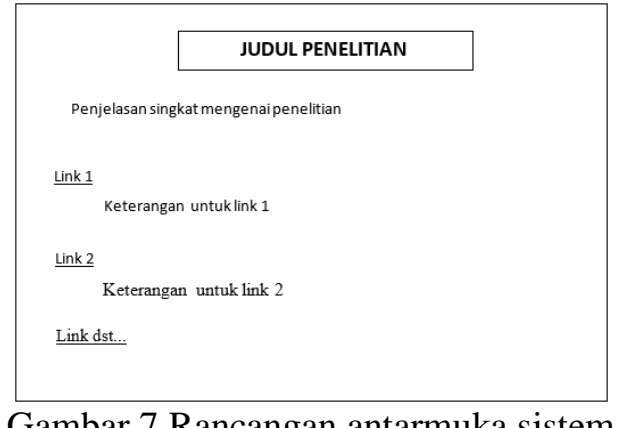

Gambar 7 Rancangan antarmuka sistem

\section{HASIL DAN PEMBAHASAN}

\subsection{Hasil Pengujian Awal}

Pengujian awal dilakukan dengan tracking bebas sembarang tanpa memperhatikan paramater-paramater yang ada. Pengujian dilakukan untuk mendapatkan hipotesa-hipotesa tertentu, kemudian dilakukan pengujian konfirmasi untuk membuktikan hipotesa tersebut. Sehingga akan terlihat faktor yang mempengaruhi keakurasian dari GPS yang digunakan. Tampilan Google Maps berupa marker dengan warna yang berbeda yaitu pink dan hijau putih. Marker pink untuk data hasil GPS tipe cn06 dan marker putih hijau untuk GPSmap 76CSx. Berikut ini merupakan tampilan hasil tracking pada pengujian awal yang dtunjukkan pada Gambar 8 .

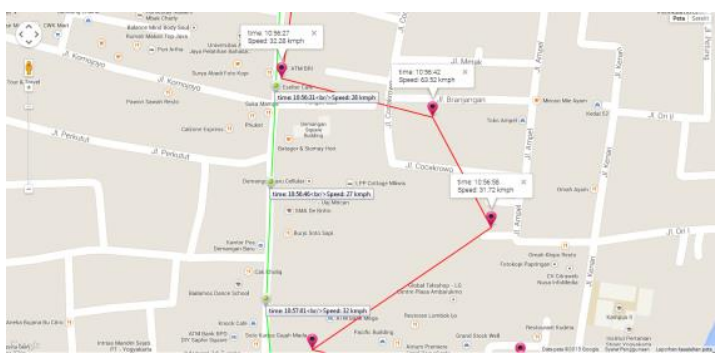

a. Hasil pengujian awal 1

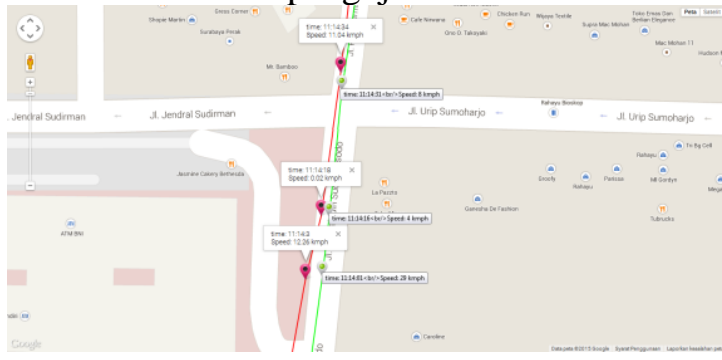

c. Hasil pengujian awal 3

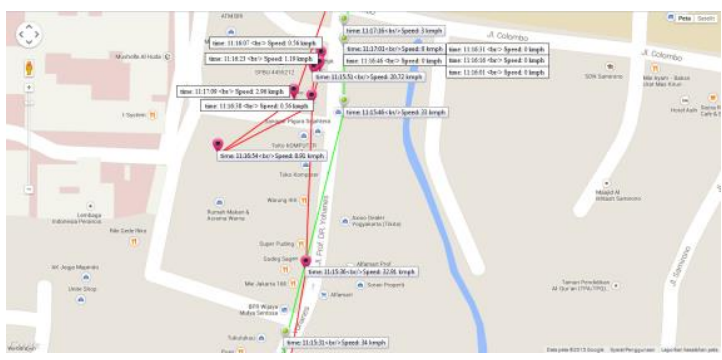

b. Hasil pengujian awal 2

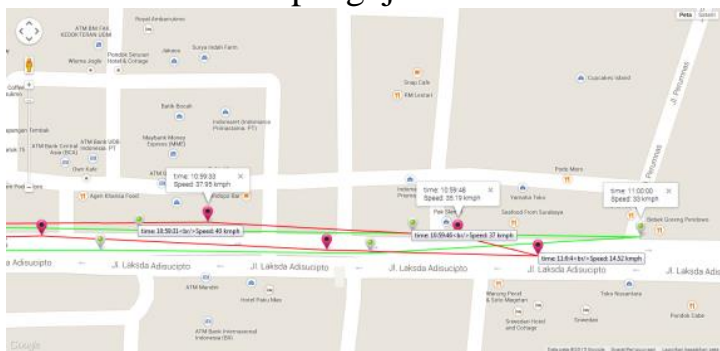

d. Hasil pengujian awal 4

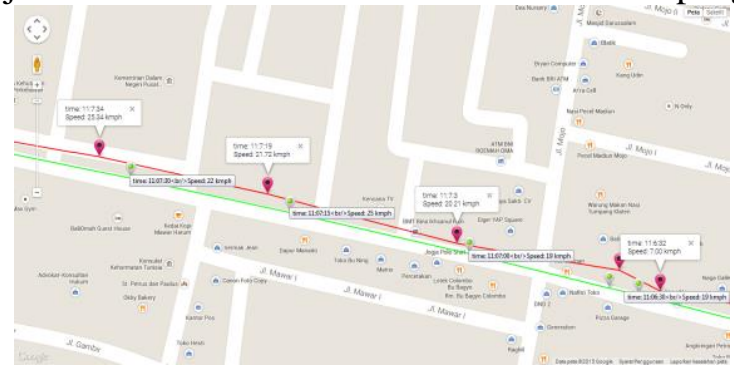

e. Hasil pengujian awal 5

Gambar 8 Hasil pengujian awal (a), (b), (c), (d), dan (e) 
Dalam Gambar 8 menunjukkan hasil pengujian awal yang telah dipilih beberapa titik koordinat. Titik-titik koordinat yang dipilih mewakili kondisi-kondisi yang berbeda, seperti kondisi jalan dan kondisi lingkungan sekitar. Gambar 8(a) terlihat titik koordinat kendaraan keluar dari jalur yg dilewati oleh kendaran. Pada saat itu kondisi kendaraan sedang berpindah posisi untuk menghindari kendaraan lain. Sehingga data yang didapatkan keluar jauh dari jalur yang seharusnya. Tetapi setelah pengambilan data berikutnya, titik koordinat akan kembali pada jalur yang dilewati kendaraan. Hal ini dikarenkan pembacaan GPS tidak hanya terkait pada sinyal yg dipancarkan oleh satelit, tetapi juga perhitungan kecepatan kendaraan. Gambar data posisi 8(b) dan 8(c) yang didapatkan pada saat berada di lampu merah. Data posisi Gambar 8(b) didapatkan saat kendaraan berada pada kecepatan tertentu kemudian tiba-tiba berhenti total, sedangkan pada Gambar 8(c) kecepatan kendaraan turun secara perlahan tanpa berhenti total dan langsung kembali ke kecepatan semula. Dari gambar menunjukkan data posisi yang didapatkan dari dua GPS relatif sama dan berdekatan. Hasil pengujian didapatkan bahwa perubahan kecepatan yang drastis akan mempengaruhi tingkat akurasi GPS. Pada Gambar 8(d) dan 8(e) diambil saat pengujian dilakukan pada jalanan lurus. Kondisi jalan yang dilalui berbeda, dimana pada Gambar 8(d) kondisi lalu lintasnya padat (banyak kendaraan) dan lingkungan sekitar terdapat banyak gedung, sedangkan pada Gambar 8(e) kondisi lalu lintas relatif lenggang (hanya ada beberapa kendaraan) dan hanya ada beberapa gedung disekitar jalan. Disajikan perhitungan menggunakan metode interpolasi untuk melihat lebih detail jarak dari GPS yang digunakan seperti pada Tabel 1 .

Tabel 1 Beberapa hasil data perhitungan pengujian awal

\begin{tabular}{|c|c|c|c|c|c|c|c|c|c|c|c|c|c|c|}
\hline Waktu A & Waktu B & target waktu & selisih 1 & selisih2 & Lat A & Lat B & \begin{tabular}{|c|c|} 
Lat B \\
terkoreksi
\end{tabular} & selisih Lat & selisih (m) & Long A & Long B & $\begin{array}{c}\text { Long B } \\
\text { terkoreksi }\end{array}$ & selisih Long & $\operatorname{selisih~(m)~}$ \\
\hline $10: 50: 28$ & & & & & $-7,767333$ & & & & & 110,385967 & & & & \\
\hline 10:50:45 & $50: 45$ & & & & $-7,767333$ & $-7,767690$ & & $-0,000357$ & $-3,4$ & 110,385967 & 110,386910 & & 443 & 10,37 \\
\hline 10:51:00 & 10:51:01 & & 15 & 10 & $6 \mid-7,767550$ & $-7,767700$ & $\mid-7,767699$ & $-0,000149$ & $-1,64$ & 110,386317 & 110,386240 & & 00035 & $-0,39$ \\
\hline 10:51:15 & $51: 16$ & 15 & 14 & 15 & $5-7,767850$ & $-7,768000$ & \begin{tabular}{|l|}
$-7,767980$ \\
\end{tabular} & $-0,000130$ & $-1,43$ & 167 & 110,387130 & & 0096 & $-1,06$ \\
\hline $10: 51: 30$ & $51: 32$ & 1:30 & 14 & 16 & $6 \mid-7,768167$ & $-7,768300$ & $-7,768263$ & $-0,000095$ & $-1,05$ & 110,3 & 110,388 & 970 & 00047 & $-0,52$ \\
\hline 10:51:45 & $51: 47$ & 1:45 & 13 & 15 & \begin{tabular}{|l|l|}
5 & $-7,768583$ \\
\end{tabular} & $-7,768590$ & \begin{tabular}{|l|}
7,768551 \\
\end{tabular} & 0,000032 & 0,35 & 110,389033 & 110,389000 & 110,388879 & 000154 & $-1,70$ \\
\hline 10:52:00 & $52: 03$ & 2:00 & 13 & 16 & $6 \mid-7,769067$ & $-7,769190$ & $\mid-7,769078$ & $-0,000011$ & $-0,12$ & 110,389067 & 110,389070 & $\mid 110,389057$ & $-0,000010$ & $-0,11$ \\
\hline $10: 52: 15$ & :52:18 & 2:15 & 12 & 15 & $5-7,769633$ & $-7,769650$ & \begin{tabular}{|l|}
$-7,769558$ \\
\end{tabular} & 0,000075 & 0,82 & 110,388883 & 110,389090 & 89086 & 00203 & 2,23 \\
\hline $10: 52: 30$ & $52: 34$ & 30 & 12 & 16 & $6 \mid-7,770017$ & $-7,770050$ & $-7,769950$ & 0,000067 & 0,74 & & 110,389940 & 1 & 0110 & 1,22 \\
\hline $10: 52: 45$ & $2: 49$ & $2: 45$ & 11 & 15 & $5-7,770183$ & $-7,770230$ & $-7,770182$ & 0,000001 & 0,01 & 110,390183 & 110,390190 & 90123 & 00060 & $-0,66$ \\
\hline 10:53:00 & $53: 05$ & 3:00 & 11 & 16 & $6 \cdot-7,770300$ & $-7,770520$ & $-7,770429$ & $-0,000129$ & $-1,42$ & 110,390300 & 110,390190 & 110,390190 & 000110 & $-1,21$ \\
\hline $10: 53: 16$ & $10: 53: 20$ & $3: 16$ & 11 & 15 & $5-7,771533$ & $-7,771890$ & \begin{tabular}{|l|}
$-7,771525$ \\
\end{tabular} & 0,000008 & 0,09 & 110,389867 & 110,389900 & 389977 & 00110 & 1,21 \\
\hline 10:53:31 & 10:53:36 & $3: 31$ & 11 & 16 & $6 \cdot-7,772917$ & $-7,773160$ & $-7,772763 \mid$ & 0,000154 & 1,69 & 110,389600 & 110,389620 & 89708 & 00107 & 1,18 \\
\hline 10:53:46 & $53: 51$ & 3:46 & 10 & 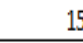 & $5-7,773417$ & $-7,773840$ & $-7,773613$ & $-0,000196$ & $-2,16$ & 110,389500 & 110,389450 & 89507 & 00007 & 0,07 \\
\hline :54:01 & 4:07 & 01 & 10 & 16 & $6 \mid-7,7$ & $-7,774190$ & $\mid-7,774059$ & $-0,000626$ & $-6,88$ & 110 & 110,389700 & 9606 & 00206 & 2,27 \\
\hline $10: 54: 16$ & $: 54: 22$ & $4: 16$ & 9 & 15 & $5 \mid-7,774367$ & $-7,774420$ & \begin{tabular}{|l|}
$-7,774328$ \\
\end{tabular} & 0,000039 & 0,43 & 110,390000 & 110,390390 & \begin{tabular}{|l|}
110,390114 \\
\end{tabular} & 00114 & 1,25 \\
\hline 10:54:31 & $10: 54: 38$ & $4: 31$ & 9 & 16 & \begin{tabular}{|c|c|}
6 & $-7,774550$ \\
\end{tabular} & $-7,774770$ & $-7,774617$ & $-0,000067$ & $-0,74$ & 110,390967 & 110,391020 & 110,390744 & 000223 & $-2,45$ \\
\hline 10:54:46 & $54: 53$ & $4: 46$ & 8 & 15 & $5-7,774733$ & $-7,775410$ & $-7,775111$ & $-0,000378$ & $-4,16$ & 110,391400 & 110,391380 & 91212 & 000188 & $-2,07$ \\
\hline $10: 55: 01$ & 10:55:09 & 5:01 & 8 & 16 & $6 \mid-7,775267$ & $-7,775550$ & $-7,775480$ & $-0,000213$ & $-2,34$ & 110 & 110,391910 & 1645 & 0112 & 1,23 \\
\hline $10: 55: 16$ & & $55: 16$ & & & $-7,775700$ & & & & & 110,392283 & & & & \\
\hline $10: 55: 31$ & $10: 55: 24$ & 5:31 & 22 & 15 & $5-7,775967$ & $-7,775840$ & $-7,775975$ & $-0,000008$ & $-0,09$ & 110,393150 & 110,392900 & 93362 & 00212 & 2,33 \\
\hline $10: 55: 46$ & :55:40 & 55:46 & 22 & 16 & $6 \cdot-7,777000$ & $-7,776520$ & $-7,776775$ & 0,000225 & 2,48 & 110,392933 & 110,393190 & 110,393299 & 000366 & 4,02 \\
\hline $10: 56: 01$ & $10: 55: 56$ & 56:01 & 21 & 16 & $6 \cdot-7,778167$ & $-7,777740$ & $-7,778121$ & 0,000046 & 0,50 & 110,392650 & 110,392840 & 110,392731 & 000081 & 0,89 \\
\hline $10: 56: 16$ & $10: 56: 11$ & 10:56:16 & 20 & 15 & $5-7,779217$ & $-7,778800$ & $-7,779153$ & 0,000064 & 0,70 & 110,392400 & 110,392600 & 110,392520 & 000120 & 1,32 \\
\hline $10: 56: 31$ & $10: 56: 27$ & $6: 31$ & 20 & 16 & $6 \cdot-7,780267$ & $-7,780080$ & $-7,780400$ & $-0,000133$ & $-1,46$ & 110,392350 & 110,392410 & 110,392363 & 000012 & 0,14 \\
\hline 10:56:46 & 10:56:42 & 5446 & 19 & 15 & \begin{tabular}{|l|l|}
5,781250 \\
\end{tabular} & $-7,780480$ & \begin{tabular}{|l|}
$-7,780587$ \\
\end{tabular} & 0,000663 & 7,3 & 110,392300 & 110,393970 & 94386 & 002086 & 22,95 \\
\hline 10:57:01 & :56:58 & 7:01 & 19 & 16 & $6 \mid-7,782450$ & $-7,781610$ & $-7,781822$ & 0,000628 & 6,91 & 110,392250 & 110,394580 & 110,394694 & 002444 & 26,89 \\
\hline 10:57:16 & $10: 57: 13$ & $10: 57: 16$ & 18 & 15 & $5-7,783083$ & $-7,782860$ & $-7,783110$ & $-0,000027$ & $-0,30$ & 110,392317 & 110,392730 & 110,392360 & 0,000043 & 0,47 \\
\hline
\end{tabular}




\subsection{Hasil Pengujian Konfirmasi Pertama}

Pengujian konfirmasi pertama dilakukan pada kondisi jalanan lenggang dengan tidak ada gedung disekitar jalan. Pengujian dilakukan dengan 3 variasi data, yaitu pengujian kecepatan konstan untuk kecepatan $40 \mathrm{~km} / \mathrm{jam}$ dan kecepatan konstan untuk kecepatan 60 $\mathrm{km} / \mathrm{jam}$ serta pengujian kecepatan tidak konstan. Karena kondisi jalanan yang lenggang, maka untuk pengujian kecepatan tidak konstan peneliti sengaja membuat kecepatan kendaraan berpindah-pindah dari $20-60 \mathrm{~km} / \mathrm{jam}$. Hasil pengujian konfirmasi pertama ditunjukkan pada Gambar 9

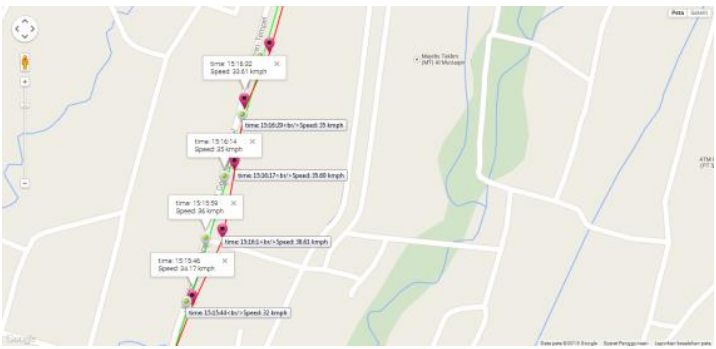

a. Hasil pengujian konfirmasi pertama 1

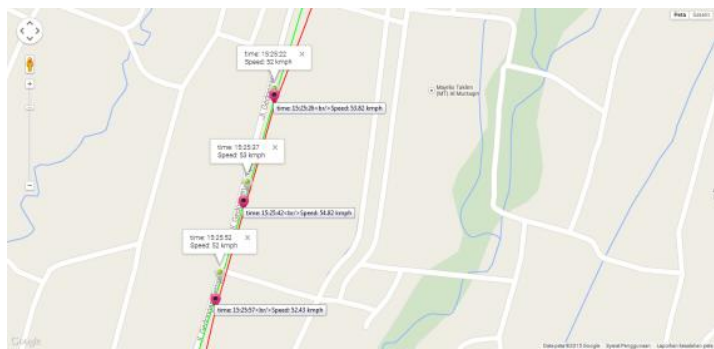

b. Hasil pengujian konfirmasi pertama 2

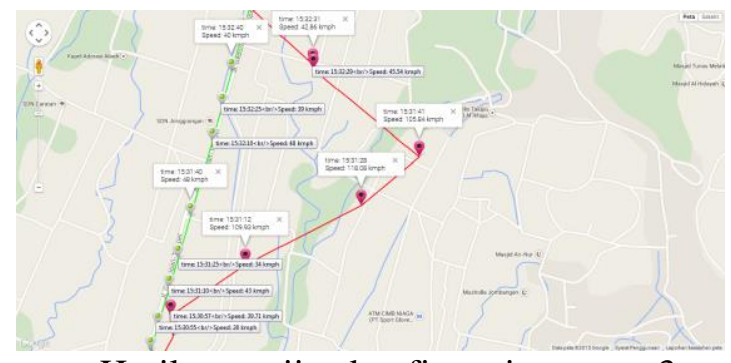

c. Hasil pengujian konfirmasi pertama 3

Gambar 9 Hasil pengujian konfirmasi pertama (a), (b), dan (c)

Dari hasil data pengujian konfirmasi pertama masing-masing pengujian pada kecepatan konstan dan kecepatan tidak konstan. Gambar 9(a) terlihat akurasinya adalah baik karena terlihat pada gambar jarak antara kedua marker berdekatan. Sedangkan pada Gambar 9(b) untuk data awal didapatkan akurasinya adalah buruk, hal ini diduga GPS yang diuji sedang menyesuaikan kecepatan sehingga data yang diperoleh tidak stabil. Diperkirakan GPS memerlukan waktu lebih untuk mencapai kecepatan tersebut dan dijaga kekonstanannya. Tetapi dapat dilihat pada akhir pengambil data, akurasinya adalah baik. Sedangkan pada Gambar 9(c) terlihat bahwa pada beberapa titik bahkan hampir keseluruhan titik memiliki akurasi yang buruk. Selain itu GPS juga sempat kehilangan sinyal, ini menunjukkan bahwa ada data waktu yang hilang yang seharusnya pada waktu tersebut GPS mendapatkan data titik koordinat.

\subsection{Hasil Pengujian Konfirmasi Kedua}

Pada pengujian konfirmasi ketiga akan dilakukan sama halnya dengan pengujian konfirmasi kedua. Pengujian hanya akan dilakukan dengan dua variasi data, yaitu untuk kecepatan konstan dan kecepatan tidak konstan. Pengujian konfirmasi ketiga dilakukan pada kondisi jalan padat dengan banyak gedung. Adapaun hasil pengujian konfirmasi ketiga ditunjukkan pada Gambar 10. 


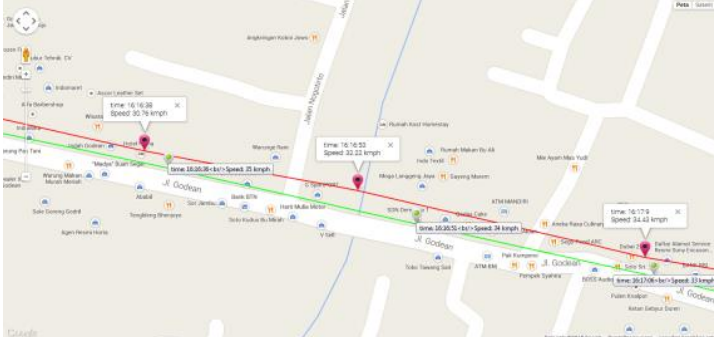

a. Hasil pengujian konfirmasi kedua (a)

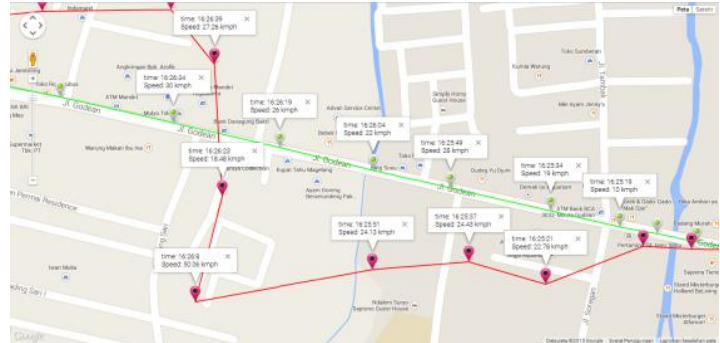

b. Hasil pengujian konfirmasi kedua (b)

Gambar 10 Hasil pengujian konfirmasi kedua (a) dan (b)

Dari Gambar 10 terlihat bahwa hasil yang didapatkan tidak berbeda jauh dengan pengujian konfirmasi sebelumnya, pada Gambar 10(a) untuk pengujian kecepatan konstan tingkat akurasinya adalah baik, berbeda untuk pengujian kecepatan tidak konstan. Pada Gambar 10(b) terlihat bahwa hasil yang didapatkan adalah data posisi pada GPS tipe cn06 keluar dari jalur yang dilewati oleh kendaraan. Seperti yang disebutkan pada pengujian awal, hal ini disebabkan pada saat pengambilan data tersebut kondisi kendaraan sedang mendahului kendaraan lainnya. Hal ini diperparah dengan kecepatan yang tidak konstan. Tapi setelah pengambilan data berikutnya dan seterusnya, data posisi akan semakin mendekati jalur kendaraan (posisi yang seharusnya). Ini berarti, GPS tipe cn06 membutuhkan waktu untuk menyesuaikan kembali dengan kondisi awal atau untuk mendapatkan titik yang sebenarnya.

\subsection{Hasil Pengujian Antarkota}

Pengujian antarkota dilakukan dengan mengaplikasikan hasil yang didapatkan pada pengujian sebelumnya. Hasil dari pengujian ini akan dibandingkan dengan pengujian sebelumnya. Akan dilihat apakah data hasil yang didapatkan berbeda jauh atau sama saja dengan pengujian sebelumnya. Gambar 11 merupakan hasil dari pengujian antarkota yang diperoleh.

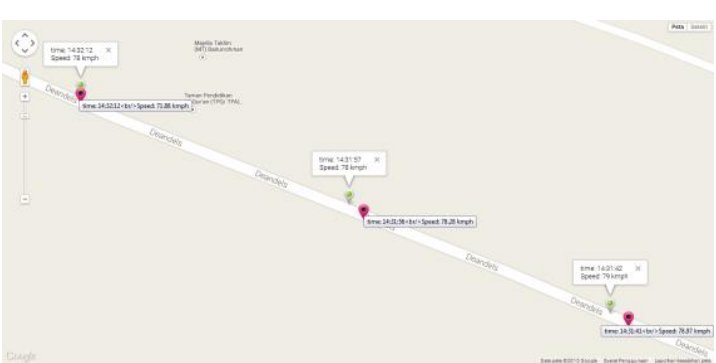

a. Hasil pengujian antarkota 1

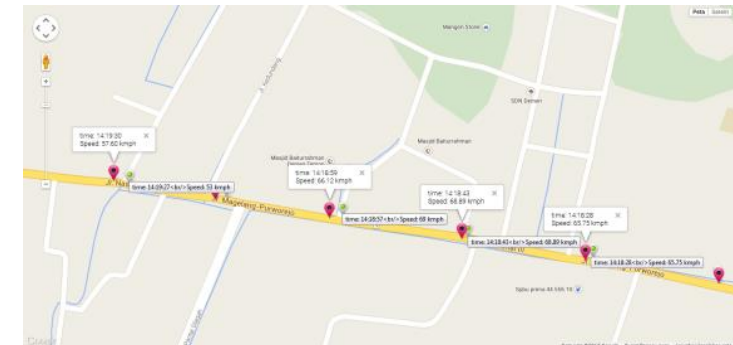

b. Hasil pengujian antarkota 2

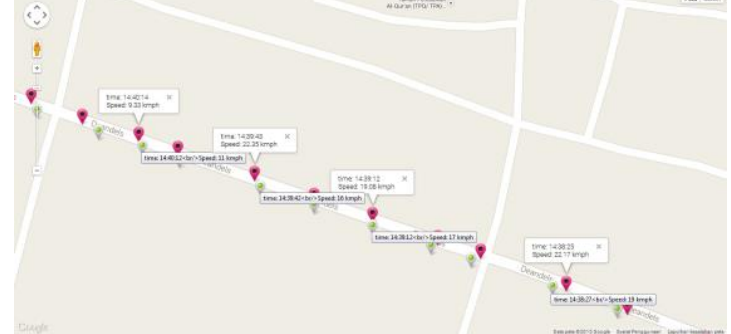

c. Hasil pengujian antarkota 3

Gambar 11 Hasil pengujian antarkota (a), (b), dan (c) 
Pada pengujian antarkota ini juga akan diambil beberapa titik untuk dianalisis lebih lanjut. Analisis terkait apakah jika kecepatan kendaraan dijaga konstan, data hasil yang didapat memiliki tingkat akurasi yang baik seperti yang didapatkan pada pengujian sebelumnya. Pengujian dilakukan dengan mengkondisikan kecepatan kendaraan konstan. Hal ini dikarenakan pada pengujian-pengujian didapatkan hasil bahwa apabila kecepatan konstan, hal-hal yang dapat mempengaruhi pembacaan GPS dan menyebabkan GPS kehilangan sinyal tidak akan begitu berpengaruh. Terlihat dari Gambar 11(a), 11(b), dan 11(c) hasil yang didapatkan adalah keakrusiannya relatif konstan dan tidak ada data yang keluar dari jalur yang seharusnya.

\section{KESIMPULAN}

Berdasarkan hasil dari perancangan dan pengujian sistem secara keseluruhan dapat disimpulkan bahwa:

1. Tingkat akurasi data posisi uji GPS tracking untuk GPS tipe cn06 sangat dipengaruhi oleh kecepatan kendaraan yang digunakan.

2. Besar kecil kecepatan yaitu untuk kecepatan 20 km/jam, 40 km/jam, 60 km/jam, dan 80 $\mathrm{km} / \mathrm{jam}$ tidak begitu mempengaruhi akurasi data hasil asalkan kecepatan kendaraan konstan.

3. Kondisi lingkungan sekitar yang dapat mempengaruhi akurasi data hasil seperti gedunggedung tinggi, banyak pohon, tidak akan begitu berpengaruh asalkan kecepatan kendaraan dijaga konstan.

4. Kecepatan yang tidak konstan selain menyebabkan data hasil menjadi tidak akurat juga menyebabkan GPS dapat kehilangan sinyal.

5. Pengujian yang dilakukan dalam skala antarkota didapatkan hasil bahwa tidak ada perbedaan dengan pengujian lainnya, yaitu faktor penting dalam keakurasian data posisi adalah kecepatan.

\section{SARAN}

Berikut adalah saran dari penulis terkait penelitian yang telah dilakukan sebagai bahan perbaikan di masa yang akan datang:

1. Perlu dilakukan penelitian lebih lanjut untuk uji GPS Tracking menggunakan modul GSM/GPRS agar data yang dihasilkan dapat langsung dikirimkan ke server dan langsung ditampilkan dalam bentuk marker pada Google Maps.

2. Pada tampilan antarmuka sistem perlu ditambahkan beberapa fitur agar tampilan lebih menarik.

\section{DAFTAR PUSTAKA}

[1] Prihtadi, 2010, Akurasi dan Presisi. Tersedia pada :

http://hafizhprihtiadi.community.undip.ac.id/tag/akurasi-dan-presisi/, diakses pada 27 Maret 2015.

[2] Ernastuti, 2010. Sistem Pelacak Rute Kendaraan dengan Tekonologi GPS dan GPRS. Tersedia pada :

http://www.gunadarma.ac.id/library/articles/postgraduate/informationsystem/Sistem\%20Informasi\%20Bisnis/Artikel_92207017.pdf, diakses pada 9 September 2014.

[3] Ramli, R., 2011, Alat Pemantau Posisi Kendaraan dengan Menggunakan Modul GPS/GSM SIM508 Berbasis Mikrokontroler ATMega12, Skripsi, Jurusan Elektronika dan Instrumentasi FMIPA UGM, Yogyakarta. 
[4] Haqqi, M. F., 2014, Mengenal Regex dalam PHP. Tersedia pada :

http://hm.if.undip.ac.id/pojokdiklat/webtutor/mengenal-regex-dalam-php/. diakses pada 25 Maret 2015.

[5] Ospriyono, H., 2013, Tutorial HTML (Hypertext Markup Language) Menggunakan Teks Editor Notepad/Notepad++. Tersedia pada: http://dosen.unived.ac.id/hari/wpcontent/uploads/sites/3/2013/03/hariaspriyono-dasarwebdanhtml.pdf, diakses pada 25 Maret 2015 